\title{
Theoretical Study of Hydrogen Bond Formation in Trimethylene Glycol-Water Complex
}

\author{
Snehanshu Pal and T. K. Kundu \\ Department of Metallurgical and Materials Engineering, Indian Institute of Technology Kharagpur, West Bengal, \\ Kharagpur 721302, India \\ Correspondence should be addressed to Snehanshu Pal, snehanshu.iitkgp.phd@gmail.com
}

Received 30 August 2012; Accepted 18 September 2012

Academic Editors: J. G. Han, T. Kar, and A. Vergara

Copyright ( $\odot 2012$ S. Pal and T. K. Kundu. This is an open access article distributed under the Creative Commons Attribution License, which permits unrestricted use, distribution, and reproduction in any medium, provided the original work is properly cited.

A detailed quantum chemical calculation based study of hydrogen bond formation in trimethylene glycol- (TMG-) water complex has been performed by Hatree-Fock (HF) method, second-order Møller-Plesset perturbation theory (MP2), density functional theory (DFT), and density functional theory with dispersion function (DFT-D) using 6-31++G(d,p) basis set. B3LYP DFT-D, WB97XD, M06, and M06-2X functionals are used to capture highly dispersive hydrogen bond formation. Geometrical parameters, interaction energy, deviation of potential energy curve of hydrogen-bonded $\mathrm{O}-\mathrm{H}$ from that of free $\mathrm{O}-\mathrm{H}$, natural bond orbital (NBO), atom in molecule (AIM), charge transfer, and red shift are investigated. It is observed that hydrogen bond between TMG and water molecule is stronger in case of TMG acting as proton donor compared to that of water acting as proton donor, and dilute TMG solution would inhibit water cluster formation.

\section{Introduction}

A hydrogen bond is an attractive donor-acceptor interaction, in which generally, the donor atoms are electronegative compared to hydrogen, and acceptor atoms have unshared lone pair electrons $[1,2]$. The hydrogen bond has crucial impacts on many aspects of chemical and biological systems, and accordingly, hydrogen bond interaction has been an important research topic for several decades. The hydrogen bond also plays a significant role in formation of clathrate hydrate in marine sediments and below permafrost regions, which is considered to be significant future energy source $[3,4]$. Global warming due to aleatory decomposition of methane hydrate [5] and hazards in petroleum industry owing to formation of gas hydrate in oil pipe line are of great concern $[6,7]$. Controlled inhibition of gas hydrate formation is thus, very important, and various thermodynamic and kinetic inhibitors can break hydrogen-bonded network of clathrate structure by forming itself comparatively stronger hydrogen bond with water molecules of clathrate. Knowledge of hydrogen bond interaction is essential to identify potential gas hydrate inhibitor and design effective gas hydrate inhibitor. Trimethylene glycol being a polar compound can be a potential gas hydrate inhibitor as well as antifreeze reagent $[7,8]$.

$\mathrm{Ab}$ initio calculation is one of the most appropriate ways to obtain perspicuous understanding of hydrogen bond interaction and its impact on gas hydrate inhibition. Density functional theory (DFT) and atom in molecule (AIM) study of strong dihydrogen bonds [10] and resonance-assisted hydrogen bond [11] have been performed. Several theoretical studies of hydrogen bond interaction have been carried out for different systems like water complex [12, 13], dichlorine monoxide-hydroxyl radical system [14], tetrahydrofuranwater complex [15, 16], and methanol-water complex [17]. In one word, the literature of quantum chemical analysis of hydrogen bond interaction for various complex is well enriched [18-23]. Electronic structure-based studies on hydrogen bond formation between a molecule having two hydroxyl groups (like trimethylene glycol) and water have 
not been reported in the literature. Explicit study of interaction between trimethylene glycol and water is necessary to reveal the effect of a molecule having two hydroxyl groups on intermolecular and intramolecular hydrogen bond formation possibilities. This electronic structure-based insights on hydrogen bond formation can help in scientific understanding on application of trimethylene glycol as a gas hydrate inhibitor.

Our objective is to report a detailed theoretical analysis to comprehend the electronic nature of the hydrogen bond formation in trimethylene glycol-water system and its property using Hartree Fock, Møller-Plesset truncated at secondorder (MP2), density function theory (DFT), and density functional theory with dispersion function (DFT-D). This study will help to conceptualize the nitty-gritty of hydrogen bond formation and its effect on vibrational spectra, natural bond orbital in trimethylene glycol-water complex.

\section{Computational Detail}

Geometry optimization, determination of interaction energy, and natural bond orbital (NBO) analysis have been carried out using Hatree Fock (HF) [24] method, second-order Møller-Plesset perturbation theory (MP2) [25], density functional theory (DFT) $[26,27]$, and density functional theory with dispersion function (DFT-D) [28]. The calculations for DFT and DFT-D levels of theory have been performed using different functional, namely, B3LYP [29, 30], WB97XD [31], M06 [32], and M062X [32]. As polarity [33], of molecule has great influence on intermolecular hydrogen bonding, hydrogen bondforming orbitals require larger space occupation [34]. Thus, diffuse and polarization functions augmented split valence $6-31++G(d, p)$ basis set is used for better description of molecular orbitals for geometry optimization and $\mathrm{NBO}$ analysis. Frequency calculation as well as AIM analysis have been performed using WB97XD/6-31++G(d,p) level of theory. Since hydrogen bonding is a kind of van der Waals type interaction, additional dispersion function with density functional theory, that is, DFT-D-based calculation has also been performed.

Interaction energy $\left(\Delta E_{\mathrm{HBF}}\right)$ for hydrogen-bonded complex is calculated as the difference between the energy of hydrogen-bonded complex and the summation of the energies of each component monomer [35] as given in (1),

$$
\Delta E_{\mathrm{HBF}}=E_{\text {complex }}-\sum E_{\text {component }}
$$

where $E_{\text {complex }}$ and $E_{\text {component }}$ are optimized energy of hydrogen-bonded complex and each individual component monomer, respectively. Interaction energies have corrected for the basis set superposition error (BSSE) by virtue of counterpoise method [36]. A hydrogen-bonded complex is more stable if interaction energy is more negative compared to other hydrogen-bonded configurations.

Donor-acceptor interaction strength between filled orbital of the donor $\left(\Phi_{i}\right)$ and the empty orbital of acceptor $\left(\Phi_{j}\right)$ in case of natural bond orbital (NBO) analysis $[37,38]$ has been determined by second-order perturbation energy $\left(\Delta E_{i j}^{(2)}\right)$ calculated using $(2)$,

$$
\Delta E_{i j}^{(2)}=2 \frac{\left\langle\phi_{i}\left|F_{i j}\right| \phi_{j}\right\rangle^{2}}{\varepsilon_{i}-\varepsilon_{j}},
$$

where $\varepsilon_{i}$ and $\varepsilon_{j}$ are NBO energies, and $F_{i j}$ is Fock matrix element between the $i$ and $j \mathrm{NBO}$ orbitals. NBO analysis reveals the intra- and intermolecular interactions, and it is one of the appropriate methods for investigating hyperconjugative interactions [39].

Red shift in vibrational spectroscopy of conventional hydrogen-bonded structures arises from hyper-conjugation interaction [40]. Atom in molecule (AIM) study using Bader theory [41] has been performed as it is very effective for evaluating topological parameters of hydrogen bonds.

All the calculations have been carried out using Gaussian 09 software package [42]. Discovery Studio v3.1 of Accelrys software inc. is used for visualization of molecules. Vibrational frequency is calculated using 0.975 scaling factor [43].

\section{Result and Discussion}

Three possible conformations of trimethylene glycol denoted by TMG-1, TMG-2, and TMG-3 have been optimized using WB97XD/6-31++G(d,p) and shown in Figure 1. The TMG2 conformation is found to be most stable as calculated relative energies of TMG-1 $(3.77 \mathrm{kcal} / \mathrm{mol})$ and TMG-3 $(3.14 \mathrm{kcal} / \mathrm{mol})$ isomers with respect to TMG-2 isomer are positive. This is because of intramolecular hydrogen bond formation in TMG-2 conformation. Detailed study of hydrogen bond interaction between water and TMG-2 conformation has been reported in this paper, and TMG-2 conformation is described as TMG. The optimized structures of TMG dimer, water dimer, TMG and one water complex considering either TMG or water as a proton donor (referred as TD and WD, resp.), and TMG + two water complex using WB97XD/6-31++G(d,p) calculation are shown in Figure 2. Here it is observed that intramolecular hydrogen bond distance (O12 - H H5) of TMG molecule increases in presence of water in WD conformation. It is also found that intermolecular hydrogen bond distances between TMG and water are less than intramolecular hydrogen bond distance (O12 * H H ) for TMG(TD)-one water complex and TMG + 2 water complexes. The intermolecular hydrogen bond in TMG + 1 water complex (TD) is smaller in length and consequently stronger than that of water dimer as evident in Figure 2. The calculated structural parameters using 6$31++G(d, p)$ basis set and different levels of theory are summarized in Tables $1(\mathrm{a})$ and $1(\mathrm{~b})$. It is identified that B3LYP DFT-D [44], parameterized functional such as M06-, M06-2x-, and WB97XD-based methods which consider attractive dispersion force, show shorter hydrogen bond distances compared to HF theory-based calculation for all the systems. It is observed from Table 1(a), hydrogen bond angle values for intramolecular hydrogen bonds $\left(\mathrm{A}_{\mathrm{O}} \cdots \mathrm{H}-\mathrm{O}\right.$, O12 * H5-O4) of TMG molecule are less than hydrogen bond angle for intermolecular hydrogen bonds between 
TABle 1: (a) Calculated hydrogen bond distances $\left(\mathrm{d}_{\mathrm{O} \cdots \mathrm{H}}, \AA\right)$, hydrogen bond angles $\left(\mathrm{A}_{\mathrm{O} \cdots \mathrm{H}}\right.$, degree), dipole moment (D, debye) for single TMG, and TMG $-n$ water complex $(n=1,2)$ using $6-31++\mathrm{G}(\mathrm{d}, \mathrm{p})$ basis set and various methods. (b) Calculated hydrogen bond distances $\left(\mathrm{d}_{\mathrm{O}} \cdots \mathrm{H}, \AA\right)$, hydrogen bond angles $\left(\mathrm{A}_{\mathrm{O} \cdots \mathrm{H}}\right.$, degree $)$, dipole moment (D, debye) for water dimer, and TMG dimer using 6-31++G(d,p) basis set and various methods.

(a)

\begin{tabular}{|c|c|c|c|c|c|c|c|c|}
\hline \multirow{2}{*}{ System } & \multirow{2}{*}{ Parameters } & \multicolumn{7}{|c|}{ Methods } \\
\hline & & MP2 & WB97XD & MO6-2X & B3LYP DFTD & MO6 & B3LYP & $\mathrm{HF}$ \\
\hline \multirow{3}{*}{ TMG } & $\mathrm{d}_{\mathrm{O} \cdots \mathrm{H}}, \mathrm{O} 12 \cdots \mathrm{H} 5$ & 2.01 & 2.02 & 2.02 & 2.03 & 2.04 & 2.04 & 2.12 \\
\hline & $\mathrm{A}_{\mathrm{O} \cdots \mathrm{H}}, \mathrm{O} 12 \cdots \mathrm{H} 5-\mathrm{O} 4$ & 137.17 & 137.36 & 135.62 & 138.00 & 136.10 & 137.45 & 133.52 \\
\hline & $\mathrm{D}$ & 4.13 & 3.85 & 3.82 & 3.82 & 3.78 & 3.82 & 3.90 \\
\hline \multirow{5}{*}{ TMG + 1 water complex (TD) } & $\mathrm{d}_{\mathrm{O} \cdots \mathrm{H}}, \mathrm{O} 14 \cdots \mathrm{H} 13$ & 1.89 & 1.87 & 1.88 & 1.85 & 1.90 & 1.89 & 2.01 \\
\hline & $\mathrm{d}_{\mathrm{O} \cdots \mathrm{H}}, \mathrm{O} 12 \cdots \mathrm{H} 5$ & 1.96 & 1.97 & 1.98 & 1.97 & 1.98 & 1.98 & 2.08 \\
\hline & $\mathrm{A}_{\mathrm{O} \cdots \mathrm{H}}, \mathrm{O} 14 \cdots \mathrm{H} 13-\mathrm{O} 12$ & 179.34 & 179.81 & 172.01 & 178.91 & 166.1 & 177.74 & 179.73 \\
\hline & $\mathrm{A}_{\mathrm{O} \cdots \mathrm{H}}, \mathrm{O} 12 \cdots \mathrm{H} 5-\mathrm{O} 4$ & 139.93 & 140.21 & 137.76 & 141.10 & 139.0 & 140.29 & 135.43 \\
\hline & $\mathrm{D}$ & 5.45 & 5.14 & 5.61 & 4.96 & 5.77 & 5.04 & 5.35 \\
\hline \multirow{7}{*}{ TMG + 1 water complex (WD) } & $\mathrm{d}_{\mathrm{O} \cdots \mathrm{H}}, \mathrm{O} 12 \cdots \mathrm{H} 14$ & 2.15 & 2.15 & 2.13 & 2.18 & 2.18 & 2.23 & 2.27 \\
\hline & $\mathrm{d}_{\mathrm{O} \cdots \mathrm{H}}, \mathrm{O} 4 \cdots \mathrm{H} 16$ & 2.29 & 2.18 & 2.16 & 2.09 & 2.15 & 2.21 & 2.46 \\
\hline & $\mathrm{d}_{\mathrm{O} \cdots \mathrm{H}}, \mathrm{O} 12 \cdots \mathrm{H} 5$ & 2.08 & 2.09 & 2.08 & 2.08 & 2.08 & 2.11 & 2.19 \\
\hline & $\mathrm{A}_{\mathrm{O} \cdots \mathrm{H}}, \mathrm{O} 12 \cdots \mathrm{H} 14-\mathrm{O} 15$ & 153.46 & 150.23 & 150.60 & 145.10 & 147.59 & 149.53 & 156.83 \\
\hline & $\mathrm{A}_{\mathrm{O} \cdots \mathrm{H}}, \mathrm{O} 4 \cdots \mathrm{H} 16-\mathrm{O} 15$ & 137.16 & 140.56 & 138.92 & 145.31 & 142.07 & 141.43 & 132.04 \\
\hline & $\mathrm{A}_{\mathrm{O} \cdots \mathrm{H}}, \mathrm{O} 12 \cdots \mathrm{H} 5-\mathrm{O} 4$ & 129.04 & 129.55 & 127.96 & 131.17 & 129.46 & 129.48 & 126.30 \\
\hline & $\mathrm{D}$ & 5.84 & 5.56 & 5.44 & 5.58 & 5.51 & 5.67 & 5.55 \\
\hline \multirow{9}{*}{ TMG + 2 water complex } & $\mathrm{d}_{\mathrm{O} \cdots \mathrm{H}}, \mathrm{O} 12 \cdots \mathrm{H} 16$ & 1.93 & 1.88 & 1.92 & 1.85 & 1.92 & 1.92 & 2.07 \\
\hline & $\mathrm{d}_{\mathrm{O} \cdots \mathrm{H}}, \mathrm{O} 14 \cdots \mathrm{H} 18$ & 2.03 & 1.98 & 2.00 & 1.96 & 2.01 & 2.01 & 2.16 \\
\hline & $\mathrm{d}_{\mathrm{O} \cdots \mathrm{H}}, \mathrm{O} 4 \cdots \mathrm{H} 19$ & 2.07 & 2.04 & 2.03 & 2.01 & 2.04 & 2.08 & 2.19 \\
\hline & $\mathrm{d}_{\mathrm{O} \cdots \mathrm{H}}, \mathrm{O} 12 \cdots \mathrm{H} 5$ & 2.08 & 2.09 & 2.05 & 2.10 & 2.06 & 2.13 & 2.20 \\
\hline & $\mathrm{A}_{\mathrm{O} \cdots \mathrm{H}}, \mathrm{O} 12 \cdots \mathrm{H} 16-\mathrm{O} 14$ & 167.66 & 171.38 & 159.54 & 170.48 & 160.10 & 168.10 & 170.42 \\
\hline & $\mathrm{A}_{\mathrm{O} \cdots \mathrm{H}}, \mathrm{O} 14 \cdots \mathrm{H} 18-\mathrm{O} 17$ & 159.62 & 160.19 & 161.95 & 160.01 & 161.85 & 160.78 & 158.30 \\
\hline & $\mathrm{A}_{\mathrm{O} \cdots \mathrm{H}}, \mathrm{O} 4 \cdots \mathrm{H} 19-\mathrm{O} 17$ & 153.14 & 152.70 & 151.64 & 154.50 & 153.11 & 154.97 & 154.52 \\
\hline & $\mathrm{A}_{\mathrm{O} \cdots \mathrm{H}}, \mathrm{O} 12 \cdots \mathrm{H} 5-\mathrm{O} 4$ & 134.18 & 134.34 & 133.78 & 134.72 & 134.33 & 133.69 & 129.97 \\
\hline & $\mathrm{D}$ & 8.09 & 7.58 & 7.10 & 7.43 & 7.09 & 7.60 & 7.90 \\
\hline
\end{tabular}

(b)

\begin{tabular}{|c|c|c|c|c|c|c|c|c|}
\hline \multirow{2}{*}{ System } & \multirow{2}{*}{ Parameters } & \multicolumn{7}{|c|}{ Methods } \\
\hline & & MP2 & WB97XD & MO6-2X & B3LYP DFTD & MO6 & B3LYP & $\mathrm{HF}$ \\
\hline \multirow{3}{*}{ Water dimer } & $\mathrm{d}_{\mathrm{O} \cdots \mathrm{H}}, \mathrm{O} 1 \cdots \mathrm{H} 6$ & 1.98 & 1.99 & 1.99 & 1.98 & 1.98 & 1.98 & 2.01 \\
\hline & $\mathrm{A}_{\mathrm{O} \cdots \mathrm{H}}, \mathrm{O} 1 \cdots \mathrm{H} 6-\mathrm{O} 2$ & 175.61 & 175.04 & 172.63 & 174.40 & 175.05 & 174.21 & 176.21 \\
\hline & $\mathrm{D}$ & 3.29 & 3.01 & 2.98 & 2.91 & 3.09 & 3.04 & 3.28 \\
\hline \multirow{11}{*}{ TMG dimer } & $\mathrm{d}_{\mathrm{O} \cdots \mathrm{H}}, \mathrm{O} 12 \cdots \mathrm{H} 5$ & 2.0 & 2.01 & 1.89 & 1.97 & 1.89 & 2.04 & 2.12 \\
\hline & $\mathrm{d}_{\mathrm{O} \cdots \mathrm{H}}, \mathrm{O} 25 \cdots \mathrm{H} 13$ & 1.79 & 1.81 & 1.81 & 1.74 & 1.84 & 1.81 & 1.95 \\
\hline & $\mathrm{d}_{\mathrm{O} \cdots \mathrm{H}}, \mathrm{O} 4 \cdots \mathrm{H} 18$ & - & - & 1.81 & - & 1.84 & - & - \\
\hline & $\mathrm{d}_{\mathrm{O} \cdots \mathrm{H}}, \mathrm{O} 12 \cdots \mathrm{H} 18$ & 1.95 & 2.00 & - & 2.00 & - & 1.96 & 2.15 \\
\hline & $\mathrm{d}_{\mathrm{O} \cdots \mathrm{H}}, \mathrm{O} 17 \cdots \mathrm{H} 26$ & - & 2.34 & 1.89 & 2.31 & 1.90 & 2.49 & - \\
\hline & $\mathrm{A}_{\mathrm{O} \cdots \mathrm{H}}, \mathrm{O} 12 \cdots \mathrm{H} 5-\mathrm{O} 4$ & 136.76 & 136.49 & 144.21 & 140.60 & 144.81 & 139.91 & 133.99 \\
\hline & $\mathrm{A}_{\mathrm{O} \cdots \mathrm{H}}, \mathrm{O} 25 \cdots \mathrm{H} 13-\mathrm{O} 12$ & 158.08 & 156.32 & 157.47 & 161.39 & 155.67 & 157.50 & 158.65 \\
\hline & $\mathrm{A}_{\mathrm{O} \cdots \mathrm{H}}, \mathrm{O} 4 \cdots \mathrm{H} 18-\mathrm{O} 17$ & - & - & 157.46 & - & 155.76 & - & - \\
\hline & $\mathrm{A}_{\mathrm{O} \cdots \mathrm{H}}, \mathrm{O} 12 \cdots \mathrm{H} 18-\mathrm{O} 17$ & 158.78 & 156.74 & - & 143.10 & - & 155.14 & 163.54 \\
\hline & $\mathrm{A}_{\mathrm{O} \cdots \mathrm{H}}, \mathrm{O} 17 \cdots \mathrm{H} 26-\mathrm{O} 25$ & - & 114.80 & 144.19 & 116.28 & 144.77 & 108.57 & - \\
\hline & $\mathrm{D}$ & 3.22 & 2.65 & 0.0011 & 1.31 & 0.0013 & 1.67 & 3.84 \\
\hline
\end{tabular}




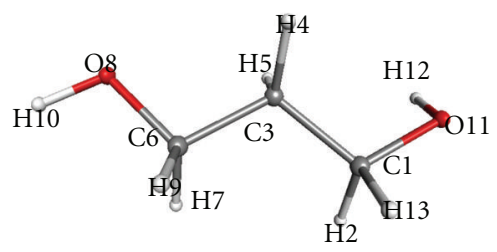

(a)

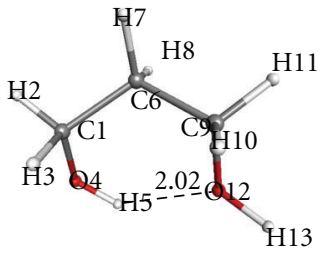

(b)

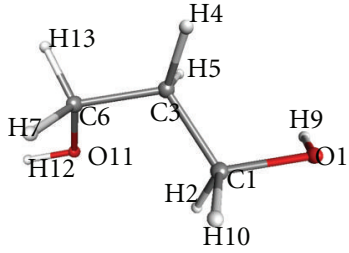

(c)

FIGURE 1: Optimized structures of different trimethylene glycol conformations such as (a) TMG-1, (b) TMG-2, and (c) TMG-3 using WB97XD/6-31++G(d,p) (colour legend: red = oxygen, black = carbon, and whitish grey = hydrogen, and black dotted line is hydrogen bond and hydrogen bond distance in $\AA$ ).

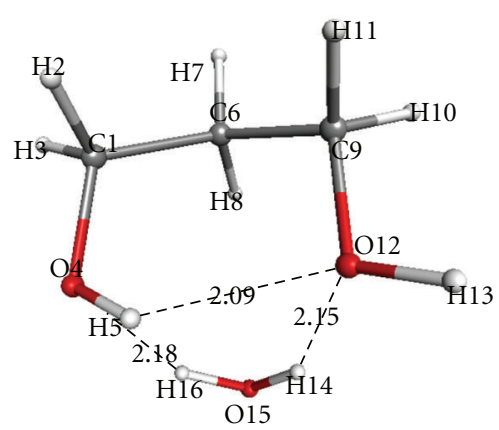

(a)

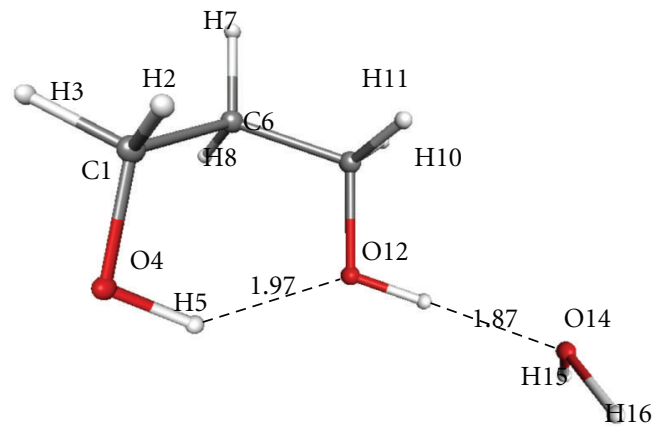

(b)

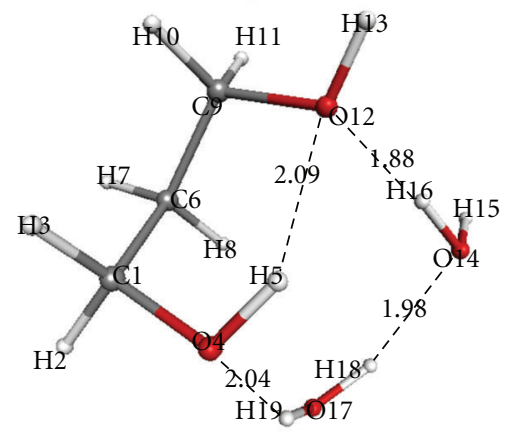

(c)

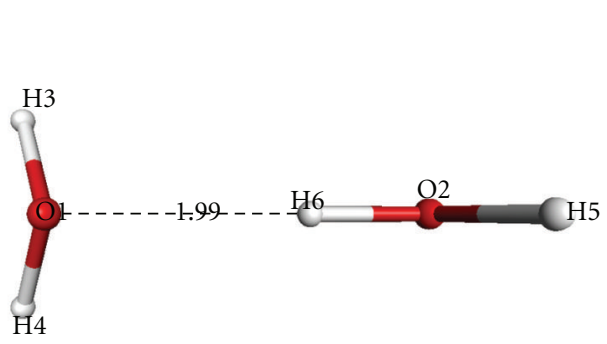

(d)

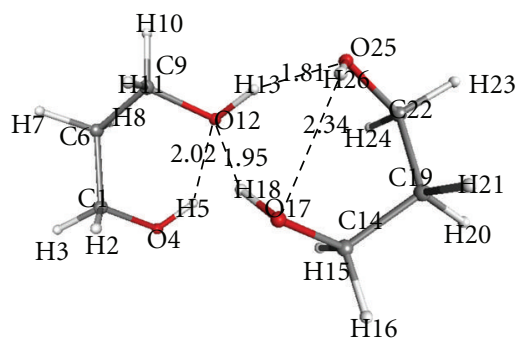

(e)

Figure 2: Optimized structures using WB97XD/6-31++G(d,p) of (a) trimethylene glycol (TMG) + 1 water complex (WD), (b) trimethylene glycol (TMG) + 1 water complex (TD), (c) trimethylene glycol (TMG) +2 water complex, (d) water dimer, and (e) trimethylene glycol dimer (colour legend: red = oxygen, black = carbon, and whitish grey = hydrogen, and black dotted line is hydrogen bond and hydrogen bond distance in $\AA$ ).

TMG and water molecule in TMG $+n$ water complex $(n=$ 1,2 ) for all calculation methods used in this paper. It is inferred based on hydrogen bond angle that the strength of intramolecular hydrogen bonds of TMG molecule are less compared to the strength of intermolecular hydrogen bonds between TMG and water molecule in TMG - n water complex $(n=1,2)$. The systems based on their dipole moment values in ascending order are water dimer $<$ TMG $<$ TMG +1 water complex (TD) $<$ TMG +1 water complex (WD) $<$ TMG +2 water complex, for all the calculation procedures performed in this work, as evident in Table 1(a). Stronger intermolecular hydrogen bond formation enhances the dipole moment as hydrogen bond formation helps superposition of $\mathrm{O} \cdot \mathrm{H}$ moment and delocalization of $\pi$ electrons in hydrogen-bonded molecular complex [45].
Calculated interaction energies with $\left(\Delta E_{\mathrm{HBF}, \mathrm{CP}}\right)$ and without $\left(\Delta E_{\mathrm{HBF}}\right)$ basis set superposition error (BSSE) correction (using counterpoise method) for TMG $+n$ water complexes $(n=1,2)$, TMG dimer, and water dimer along with number of hydrogen bonds formed are summarized in Table 2. The calculated interaction energies using HF method is less negative, indicating least hydrogen bond strength as it does not consider electron correlation. The hydrogenbonded complex having more negative interaction energy should be more stable. Therefore, the ascending order with respect to stability is TMG +1 water (WD) complex < TMG + 1 water (TD) complex $<$ TMG +2 water complex using HF, MP2, and B3LYP functional based methods, which exclude the dispersion term. The stability order in ascending sense using B3LYP DFT-D, WB97XD, M06, and M06-2X functional is water dimer $<$ TMG +1 water (TD) 


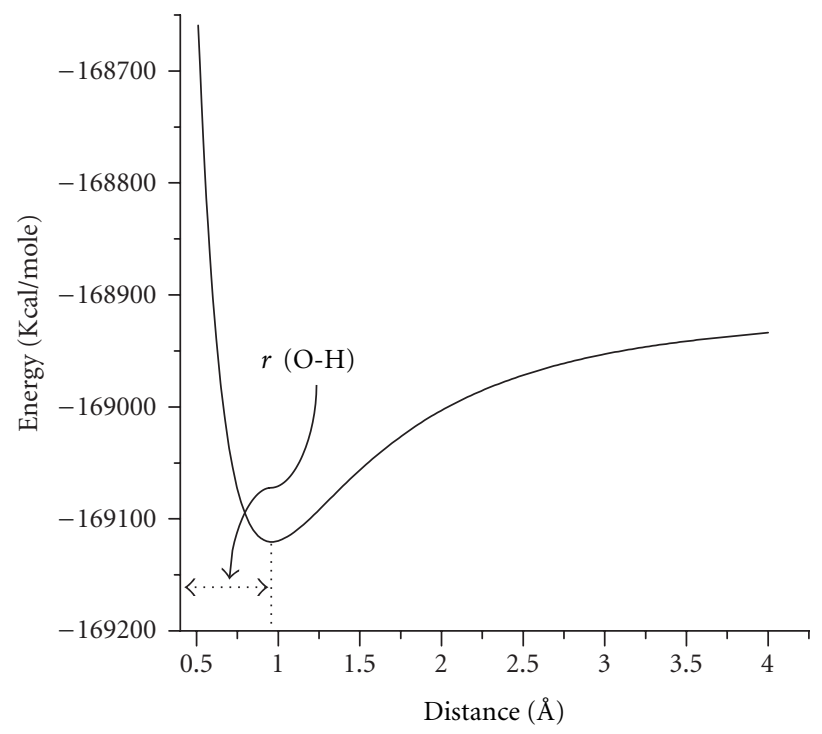

(a)

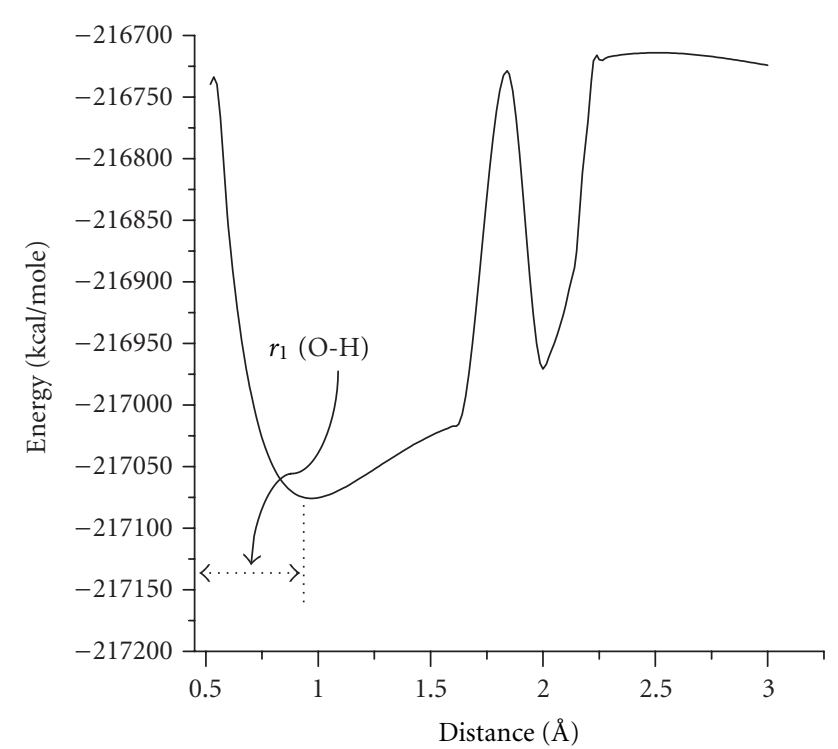

(b)

FIGURE 3: Calculated energy (kcal/mol) curve using WB97XD/6-31++G(d,p) for (a) a free bond of O-H (O12-H13) group of single TMG molecule (refer Figure 1(b)) and (b) hydrogen-bonded O-H (O12-H13) group of TMG + 1 water complex (TD) (refer Figure 2(b)).

complex $<$ TMG + 1 water $(\mathrm{WD})$ complex $<$ TMG dimer $<$ TMG +2 water complex. TMG +1 water complex (TD) forms one intermolecular hydrogen bond $(\mathrm{O} 14 \cdots \mathrm{H} 13)$, and TMG + 1 water (WD) complex form two intermolecular hydrogen bonds $(\mathrm{O} 12 \cdots \mathrm{H} 14, \mathrm{O} 4 \cdots \mathrm{H} 16)$ as shown in Figures 2(b) and 2(c). Calculation methods using functionals having dispersion terms (B3LYP DFT-D, WB97XD, M06, and M06-2X) determine more negative interaction energy for a hydrogen-bonded complex compared to that obtained by HF, MP2 and B3LYP method as evident from Table 2 . TMG has strong potential to form stable cluster with water molecules, and accordingly, dilute TMG solution would be useful as an inhibitor to restrict the formation of water cluster.

The potential energy curves for a free $\mathrm{O}-\mathrm{H}(\mathrm{O} 12-\mathrm{H} 13)$ bond of single TMG molecule and hydrogen-bonded $\mathrm{O}-\mathrm{H}$ (O12-H13) of TMG + 1 water complex (TD) are presented in Figures 3(a) and 3(b), respectively. The broadening of potential energy curve and appearance of asymmetrical double minimum in potential energy curve of hydrogenbonded $\mathrm{O}-\mathrm{H}$ reveal that a moderately strong hydrogen bond $(\mathrm{O} 14 \cdots \mathrm{H} 13)$ is formed between TMG and water molecule [2]. The interaction energy barrier is high, which provides allowances for having various energetically lower protonic states [9].

Absolute Mullikan charge difference, absolute NBO charge difference, and absolute Chelpg charge difference between intermolecular hydrogen bond-forming oxygen and hydrogen atoms are obtained by taking absolute values of the difference between charge of oxygen and charge of hydrogen atoms and summarized in Table 3 . As absolute charge differences between two atoms increase, the attractive electrostatic force between those two atoms also increases. Calculated absolute Mullikan charge difference, absolute NBO charge difference, and absolute Chelpg charge difference between intermolecular hydrogen bond-forming atoms (O14, H13) for TMG + 1 water complex (TD) are maximum and accordingly, forming strongest hydrogen bond compared to other systems for all the methods used in this paper, as shown in Table 3.

Highest occupied molecular orbital (HOMO) and lowest unoccupied molecular orbital (LUMO) of TMG and water systems, simulated by WB97XD/6-31++G(d,p) method, are presented in Figure 4. The LUMO energies of TMG $+n$ water complexes $(n=1,2)$ are less compared to that of single TMG and water molecule. The LUMO of TMG + 1 water complex (TD) originates essentially from the LUMO of water with negligible contribution of antibonding orbital of TMG, but the HOMO of the same complex arises largely from the HOMO of TMG. On the other hand, for TMG +1 water complex (WD) and TMG + 2 water complex, LUMO comes mainly from the LUMO of the TMG, and HOMO is from the intermixing of lone pairs of both TMG and water molecules. Intermolecular hydrogen bond $(\mathrm{O} 14 \cdots \mathrm{H} 13)$ of TMG +1 water complex (TD) has very high covalent character compared to two intermolecular hydrogen bonds (O12 $\cdots \mathrm{H} 14, \mathrm{O} 4 \cdots \mathrm{H} 16)$ of TMG +1 water complex (WD). It is also justified by the respective hydrogen bond lengths, that is, $1.87 \AA, 2.15 \AA$, and $2.18 \AA$ for $\mathrm{O} 14 \cdots \mathrm{H} 13, \mathrm{O} 12 \cdots \mathrm{H} 14$, and $\mathrm{O} 4 \cdots \mathrm{H} 16$, respectively, as evident in Figures 2(b) and 2(c). In case of TMG +2 water complex, the HOMO originates from major intermixing of lone pairs of TMG molecule and one water molecule (H19O17-H18) and hardly any contribution from other water molecule (H16-O14-H15). It is also found from Figure 4, that the LUMO for TMG + 2 water complex originates from major intermixing of antibonding orbital of TMG molecule and one water molecule (H19-O17-H18). The covalent 

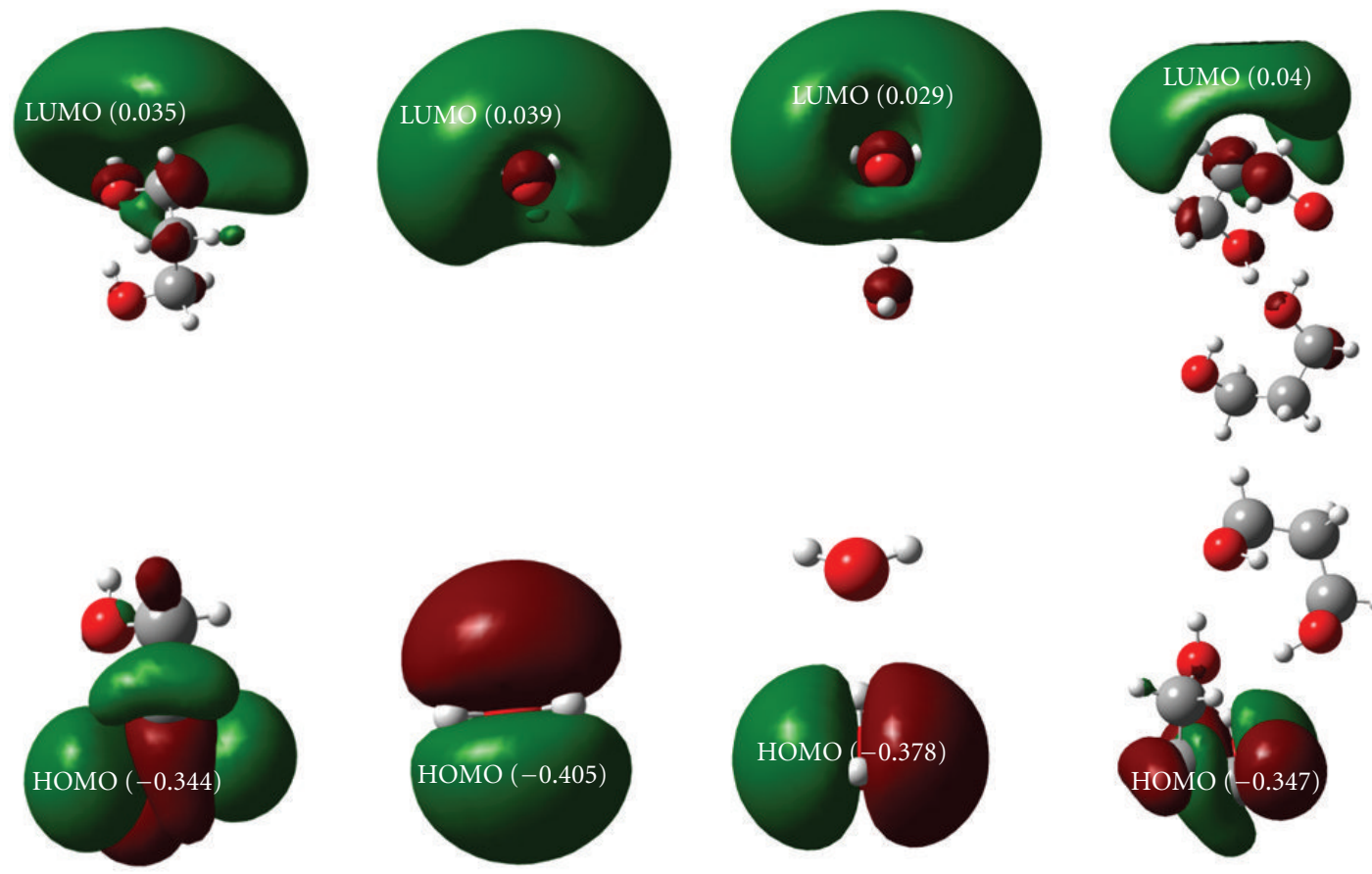

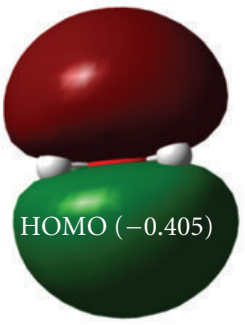

(b)

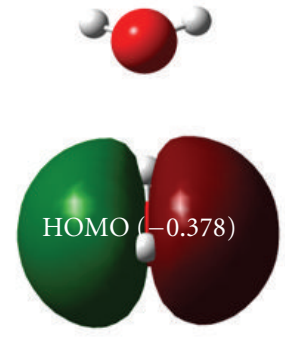

(c)

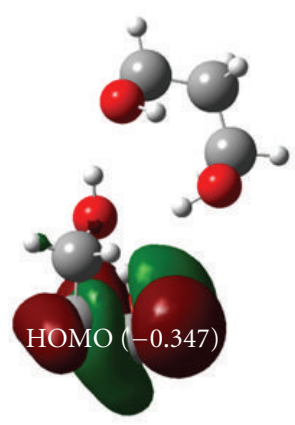

(d)
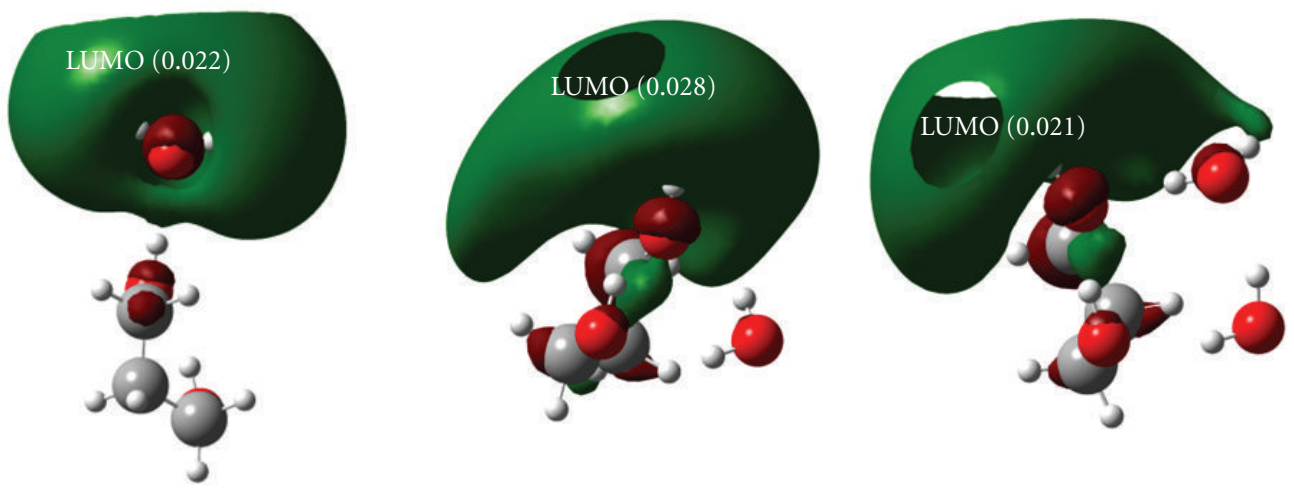

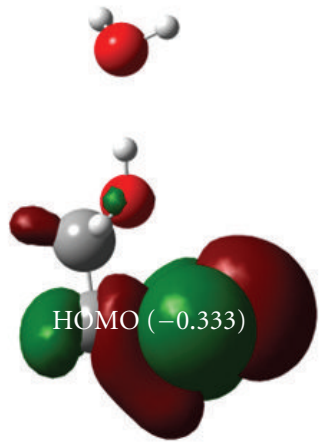

(e)

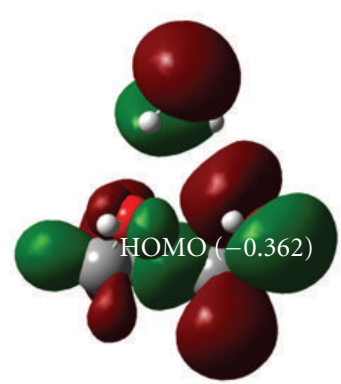

(f)

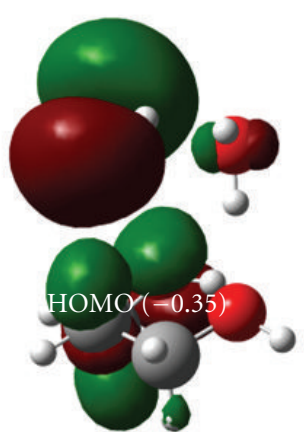

(g)

FIGURE 4: Frontier orbitals (HOMO, LUMO energies is atomic unit) of (a) TMG monomer, (b) water monomer, (c) water dimer, (d) TMG dimer, (e) TMG + 1 water complex (TD), (f) TMG + 1 water complex (WD), and (g) TMG +2 water complex by WB97XD/6-31++G(d,p) theory. 
TABLE 2: Calculated interaction energy without correction $\left(\Delta E_{\mathrm{HBF}}, \mathrm{kcal} / \mathrm{mol}\right)$, BSSE-corrected energy of hydrogen bond formation using counterpoise correction $\left(\Delta E_{\mathrm{HBF}, \mathrm{CP}}, \mathrm{kcal} / \mathrm{mol}\right)$, hydrogen bond numbers for TMG $+n$ water complex $(n=1,2)$, TMG dimer, and water dimer using 6-31++G(d,p) basis set and various methods.

\begin{tabular}{|c|c|c|c|c|}
\hline Systems & Calculation methods & $\Delta E_{\mathrm{HBF}}$ & $\Delta E_{\mathrm{HBF}, \mathrm{CP}}$ & No. of hydrogen bonds \\
\hline \multirow{7}{*}{ TMG + 1 water complex (TD) } & MP2 & -7.65 & -5.62 & \multirow{7}{*}{2} \\
\hline & $\mathrm{HF}$ & -5.64 & -4.94 & \\
\hline & B3LYP & -6.71 & -5.77 & \\
\hline & B3LYP DFT-D & -7.79 & -6.81 & \\
\hline & WB97XD & -7.42 & -6.51 & \\
\hline & M06 & -7.00 & -6.15 & \\
\hline & M062X & -7.59 & -6.63 & \\
\hline \multirow{7}{*}{ TMG + 1 water complex (WD) } & MP2 & -7.46 & -4.93 & \multirow{7}{*}{3} \\
\hline & $\mathrm{HF}$ & -4.71 & -3.88 & \\
\hline & B3LYP & -5.38 & -4.58 & \\
\hline & B3LYP DFT-D & -8.92 & -7.84 & \\
\hline & WB97XD & -8.01 & -7.01 & \\
\hline & M06 & -7.39 & -6.46 & \\
\hline & M062X & -8.48 & -7.37 & \\
\hline \multirow{7}{*}{ TMG + 2 water complex } & MP2 & -16.39 & -11.30 & \multirow{7}{*}{4} \\
\hline & $\mathrm{HF}$ & -10.80 & -9.24 & \\
\hline & B3LYP & -13.46 & -11.44 & \\
\hline & B3LYP DFT-D & -18.32 & -16.10 & \\
\hline & WB97XD & -16.91 & -14.81 & \\
\hline & M06 & -16.33 & -14.19 & \\
\hline & M062X & -17.90 & -15.51 & \\
\hline \multirow{7}{*}{ TMG dimer } & MP2 & -9.46 & -5.51 & \multirow{7}{*}{4} \\
\hline & $\mathrm{HF}$ & -4.52 & -3.51 & \\
\hline & B3LYP & -7.58 & -6.61 & \\
\hline & B3LYP-DFTD & -13.38 & -12.26 & \\
\hline & WB97XD & -9.96 & -8.90 & \\
\hline & M06 & -14.69 & -13.68 & \\
\hline & M062X & -15.18 & -13.87 & \\
\hline \multirow{7}{*}{ Water dimer } & MP2 & -6.39 & -4.83 & \multirow{7}{*}{1} \\
\hline & $\mathrm{HF}$ & -5.01 & -4.36 & \\
\hline & B3LYP & -5.97 & -5.19 & \\
\hline & B3LYP-DFTD & -6.71 & -5.95 & \\
\hline & WB97XD & -6.35 & -5.61 & \\
\hline & M06 & -5.99 & -5.25 & \\
\hline & M062X & -6.58 & -5.80 & \\
\hline
\end{tabular}

character is more prominent in one intermolecular hydrogen bond $(\mathrm{O} 12 \cdots \mathrm{H} 16)$ compared to other hydrogen bond $(\mathrm{O} 4 \cdots \mathrm{H} 19)$ in TMG +2 water complex, and consequently the $\mathrm{O} 12 \cdots \mathrm{H} 16$ hydrogen bond is comparatively more strong, which is also supported by their hydrogen bond distances shown in Figure 1(d). Mixing of the HOMO of proton donor (O12-H13-bonding orbital of TMG) with the LUMO of proton acceptor (O14 of water molecule) in TMG +1 water complex (TD) leads to decrease of electron density around $\mathrm{O} 12-\mathrm{H} 13$ bond.

The calculated second-order perturbation energies and respective occupancies for selective donor-acceptor interactions relevant to hydrogen bond formation in single TMG molecule and TMG + 1 water (TD) complex from
NBO analysis are given in Table 4. Calculated second-order perturbation energy of donor- (lone pair of O14) acceptor (antibonding orbital of O12-H13) interaction responsible for intermolecular hydrogen bonding is higher than that of donor- (lone pair of O12) acceptor (antibonding orbital of O4-H5) interaction responsible for intramolecular hydrogen bonding in TMG + 1 water complex (TD) according to all the methods used in this work. It is inferred that the intermolecular hydrogen bond is stronger than intra molecular hydrogen bond for TMG-water complex (TD) as supported by respective hydrogen bond distances.

The charge transfer (CT) energies calculated using natural energy decomposition analysis (NEDA) for TMG, TMG + 1 water complex (TD), TMG + 1 water complex 
TABle 3: Calculated absolute Mullikan charge difference, absolute NBO charge difference, and absolute Chelpg charge difference between hydrogen bond-forming atoms for TMG $+n$ water complex $(n=1,2)$ using $6-31++\mathrm{G}(\mathrm{d}, \mathrm{p})$ basis set and various methods.

\begin{tabular}{|c|c|c|c|c|c|}
\hline System & Methods & $\begin{array}{c}\text { Hydrogen } \\
\text { bond-forming } \\
\text { atoms }\end{array}$ & $\begin{array}{l}\text { Mullikan charge } \\
\text { diff. (a.u.) }\end{array}$ & $\begin{array}{l}\text { NBO charge diff. } \\
\text { (a.u.) }\end{array}$ & $\begin{array}{l}\text { Chelpg } \\
\text { charge diff. (a.u.) }\end{array}$ \\
\hline \multirow{7}{*}{ TMG + 1 water complex (TD) } & MP2 & $\mathrm{O} 14 \cdot \cdots \mathrm{H} 13$ & 1.25 & 1.54 & 1.39 \\
\hline & $\mathrm{HF}$ & $\mathrm{O} 14 \cdots \mathrm{H} 13$ & 1.23 & 1.53 & 1.43 \\
\hline & B3LYP & $\mathrm{O} 14 \cdots \mathrm{H} 13$ & 1.20 & 1.51 & 1.33 \\
\hline & B3LYP DFT-D & $\mathrm{O} 14 \cdots \mathrm{H} 13$ & 1.20 & 1.51 & 1.30 \\
\hline & WB97XD & $\mathrm{O} 14 \cdots \mathrm{H} 13$ & 1.20 & 1.52 & 1.33 \\
\hline & MO6 & $\mathrm{O} 14 \cdots \mathrm{H} 13$ & 1.21 & 1.54 & 1.36 \\
\hline & MO62X & $\mathrm{O} 14 \cdots \mathrm{H} 13$ & 1.25 & 1.54 & 1.36 \\
\hline \multirow{14}{*}{ TMG + 1 water complex (WD) } & \multirow{2}{*}{ MP2 } & $\mathrm{O} 4 \cdot \cdots \mathrm{H} 16$ & 1.02 & 1.34 & 1.14 \\
\hline & & $\mathrm{O} 12 \cdots \mathrm{H} 14$ & 1.11 & 1.36 & 1.08 \\
\hline & \multirow{2}{*}{$\mathrm{HF}$} & $\mathrm{O} 4 \cdot \cdots \mathrm{H} 16$ & 1.00 & 1.32 & 1.17 \\
\hline & & $\mathrm{O} 12 \cdots \mathrm{H} 14$ & 1.09 & 1.34 & 1.11 \\
\hline & \multirow{2}{*}{ B3LYP } & $\mathrm{O} 4 \cdot \cdots \mathrm{H} 16$ & 0.90 & 1.28 & 1.09 \\
\hline & & $\mathrm{O} 12 \cdots \mathrm{H} 14$ & 1.01 & 1.30 & 1.03 \\
\hline & \multirow{2}{*}{ B3LYP DFT-D } & $\mathrm{O} 4 \cdots \mathrm{H} 16$ & 0.91 & 1.28 & 1.09 \\
\hline & & $\mathrm{O} 12 \cdots \mathrm{H} 14$ & 1.02 & 1.30 & 1.02 \\
\hline & \multirow{2}{*}{ WB97XD } & $\mathrm{O} 4 \cdots \mathrm{H} 16$ & 0.93 & 1.29 & 1.10 \\
\hline & & $\mathrm{O} 12 \cdots \mathrm{H} 14$ & 1.05 & 1.30 & 1.03 \\
\hline & \multirow{2}{*}{ MO6 } & $\mathrm{O} 4 \cdots \mathrm{H} 16$ & 0.94 & 1.30 & 1.09 \\
\hline & & $\mathrm{O} 12 \cdots \mathrm{H} 14$ & 1.06 & 1.32 & 1.03 \\
\hline & \multirow{2}{*}{ MO62X } & $\mathrm{O} 4 \cdot \cdots \mathrm{H} 16$ & 0.97 & 1.30 & 1.09 \\
\hline & & $\mathrm{O} 12 \cdots \mathrm{H} 14$ & 1.08 & 1.31 & 1.01 \\
\hline \multirow{14}{*}{ TMG + 2 water complex } & \multirow{2}{*}{ MP2 } & 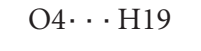 & 1.06 & 1.34 & 1.17 \\
\hline & & $\mathrm{O} 12 \cdots \mathrm{H} 16$ & 1.17 & 1.38 & 0.93 \\
\hline & \multirow{2}{*}{$\mathrm{HF}$} & O4 $\cdots$ H19 & 1.02 & 1.33 & 1.19 \\
\hline & & $\mathrm{O} 12 \cdots \mathrm{H} 16$ & 1.14 & 1.36 & 0.97 \\
\hline & \multirow{2}{*}{ B3LYP } & $\mathrm{O} 4 \cdots \mathrm{H} 19$ & 0.93 & 1.28 & 1.13 \\
\hline & & $\mathrm{O} 12 \cdots \mathrm{H} 16$ & 1.06 & 1.32 & 0.85 \\
\hline & \multirow{2}{*}{ B3LYP DFT-D } & O4 $\cdots$ H19 & 0.94 & 1.28 & 1.13 \\
\hline & & $\mathrm{O} 12 \cdots \mathrm{H} 16$ & 1.09 & 1.32 & 0.87 \\
\hline & \multirow{2}{*}{ WB97XD } & O4 $\cdots$ H19 & 0.96 & 1.29 & 1.13 \\
\hline & & $\mathrm{O} 12 \cdots \mathrm{H} 16$ & 1.10 & 1.32 & 0.89 \\
\hline & \multirow{2}{*}{ MO6 } & O4 $\cdots$ H19 & 0.99 & 1.31 & 1.00 \\
\hline & & $\mathrm{O} 12 \cdots \mathrm{H} 16$ & 1.13 & 1.34 & 0.80 \\
\hline & \multirow{2}{*}{ MO62X } & O4 $\cdots$ H19 & 1.01 & 1.30 & 1.00 \\
\hline & & $\mathrm{O} 12 \cdots \mathrm{H} 16$ & 1.15 & 1.34 & 0.79 \\
\hline
\end{tabular}

(WD), TMG + 2 water complex, water dimer, and TMG dimer are presented as bar chart in Figure 5. Charge transfer (CT) is a part of the stabilization energy of intermolecular interacting system [46], and it plays an important role in hydrogen bond formation [47, 48]. CT represents electron delocalization interaction between occupied molecular orbital of one molecule and unoccupied molecular orbital of another molecule. As TMG dimer shows lowest CT value 
TABLe 4: Calculated second-order perturbation energy $\left(\Delta E_{i j}^{(2)}, \mathrm{kcal} / \mathrm{mol}\right)$ for TMG single and TMG $-n$ water complex $(n=1,2)$ using 6-31++G(d,p) basis set and various methods.

\begin{tabular}{|c|c|c|c|c|c|c|}
\hline System & Method & Donor & $\begin{array}{c}\text { Occupancy } \\
\text { of donor }\end{array}$ & Acceptor & $\begin{array}{l}\text { Occupancy } \\
\text { of acceptor }\end{array}$ & $\Delta E_{i j}^{(2)}$ \\
\hline \multirow{7}{*}{ TMG } & MP2 & $\mathrm{LP}(2) \mathrm{O} 12$ & 1.973 & $\mathrm{BD}^{*}(1) \mathrm{O} 4-\mathrm{H} 5$ & 0.013 & 4.88 (Intra) \\
\hline & $\mathrm{HF}$ & $\mathrm{LP}(1) \mathrm{O} 12$ & 1.984 & $\mathrm{BD}^{*}(1) \mathrm{O} 4-\mathrm{H} 5$ & 0.011 & 3.07 (Intra) \\
\hline & B3LYP & $\mathrm{LP}(2) \mathrm{O} 12$ & 1.979 & $\mathrm{BD}^{*}(1) \mathrm{O} 4-\mathrm{H} 5$ & 0.019 & 4.72 (Intra) \\
\hline & B3LYP DFT-D & $\mathrm{LP}(2) \mathrm{O} 12$ & 1.962 & $\mathrm{BD}^{*}(1) \mathrm{O} 4-\mathrm{H} 5$ & 0.018 & 4.17 (Intra) \\
\hline & WB97XD & $\mathrm{LP}(2) \mathrm{O} 12$ & 1.963 & $\mathrm{BD}^{*}(1) \mathrm{O} 4-\mathrm{H} 5$ & 0.018 & 5.09 (Intra) \\
\hline & MO6 & $\mathrm{LP}(2) \mathrm{O} 12$ & 1.961 & $\mathrm{BD}^{*}(1) \mathrm{O} 4-\mathrm{H} 5$ & 0.018 & 3.20 (Intra) \\
\hline & MO62X & $\mathrm{LP}(2) \mathrm{O} 12$ & 1.965 & $\mathrm{BD}^{*}(1) \mathrm{O} 4-\mathrm{H} 5$ & 0.016 & 3.63 (Intra) \\
\hline \multirow{14}{*}{ TMG + 1 water complex (TD ) } & \multirow{2}{*}{ MP2 } & $\mathrm{LP}(2) \mathrm{O} 12$ & 1.968 & $\mathrm{BD}^{*}(1) \mathrm{O} 4-\mathrm{H} 5$ & 0.017 & 7.28 (Intra) \\
\hline & & $\mathrm{LP}(2) \mathrm{O} 14$ & 1.981 & $\mathrm{BD}^{*}(1) \mathrm{O} 12-\mathrm{H} 13$ & 0.020 & 15.79 (Inter) \\
\hline & \multirow{2}{*}{ HF } & $\mathrm{LP}(1) \mathrm{O} 12$ & 1.981 & $\mathrm{BD}^{*}(1) \mathrm{O} 4-\mathrm{H} 5$ & 0.012 & 3.74 (Intra) \\
\hline & & $\mathrm{LP}(2) \mathrm{O} 14$ & 1.988 & $\mathrm{BD}^{*}(1) \mathrm{O} 12-\mathrm{H} 13$ & 0.014 & 10.12 (Inter) \\
\hline & \multirow{2}{*}{ B3LYP } & $\mathrm{LP}(2) \mathrm{O} 12$ & 1.955 & $\mathrm{BD}^{*}(1) \mathrm{O} 4-\mathrm{H} 5$ & 0.023 & 6.03 (Intra) \\
\hline & & $\mathrm{LP}(2) \mathrm{O} 4$ & 1.978 & $\mathrm{BD}^{*}(1) \mathrm{O} 12-\mathrm{H} 13$ & 0.030 & 14.30 (Inter) \\
\hline & \multirow{2}{*}{ B3LYP DFT-D } & $\mathrm{LP}(2) \mathrm{O} 12$ & 1.952 & BD*(1)O4-H5 & 0.025 & 7.07 (Intra) \\
\hline & & $\mathrm{LP}(2) \mathrm{O} 14$ & 1.969 & $\mathrm{BD}^{*}(1) \mathrm{O} 12-\mathrm{H} 13$ & 0.033 & 16.57 (Inter) \\
\hline & \multirow{2}{*}{ WB97XD } & $\mathrm{LP}(2) \mathrm{O} 12$ & 1.956 & $\mathrm{BD}^{*}(1) \mathrm{O} 4-\mathrm{H}$ & 0.022 & 7.42 (Intra) \\
\hline & & $\mathrm{LP}(2) \mathrm{O} 14$ & 1.972 & $\mathrm{BD}^{*}(1) \mathrm{O} 12-\mathrm{H} 13$ & 0.030 & 18.04 (Inter) \\
\hline & \multirow[t]{2}{*}{ MO6 } & $\mathrm{LP}(2) \mathrm{O} 12$ & 1.953 & BD*(1)O4-H5 & 0.022 & $5.56($ Intra $)$ \\
\hline & & $\mathrm{LP}(2) \mathrm{O} 14$ & 1.976 & $\mathrm{BD}^{*}(1) \mathrm{O} 12-\mathrm{H} 13$ & 0.026 & 13.09 (Inter) \\
\hline & \multirow[t]{2}{*}{ MO62X } & $\mathrm{LP}(2) \mathrm{O} 12$ & 1.960 & $\mathrm{BD}^{*}(1) \mathrm{O} 4-\mathrm{H} 5$ & 0.019 & 5.05 (Intra) \\
\hline & & $\mathrm{LP}(2) \mathrm{O} 14$ & 1.977 & $\mathrm{BD}^{*}(1) \mathrm{O} 12-\mathrm{H} 13$ & 0.025 & 14.68 (Inter) \\
\hline
\end{tabular}

compared to that of others, TMG dimer would be having the strongest intermolecular hydrogen bond interaction. Consequently, TMG would be effective for inhibiting water cluster formation only when there is no favorable TMG dimer formation condition, that is, at low concentration of TMG.

Calculated electron density contours with hydrogen bond critical point (HBCP), total electron density, and total Laplacian electron density at HBCP using AIM analysis for TMG molecule, water dimer, and TMG + 1 water complex (TD) using WB97XD/6-31++G(d,p) method are represented in Figure 6 and Table 5, respectively. One hydrogen bond critical point is determined for TMG molecule and water dimer, but two hydrogen bond critical points are found in TMG + 1 water complex (TD). The hydrogen bond critical point $(\mathrm{HBCP})$ is a specific point between the donor and acceptor, where the gradient of electron density is zero, and it is essential evidence of hydrogen bond existence. TMG + 1 water complex (TD) has more covalence character and consequently more strength compared to water dimer as it has higher electron density at HBCP $[41,49]$ as evident in Table 5.

Calculated vibrational frequencies and IR intensities of $\mathrm{O}-\mathrm{H}$ stretching of water and TMG molecule, TMG dimer, and TMG $+n$ water complex system $(n=1,2)$ using WB97XD/6-31++G(d,p) are listed in Table 6. The red shift

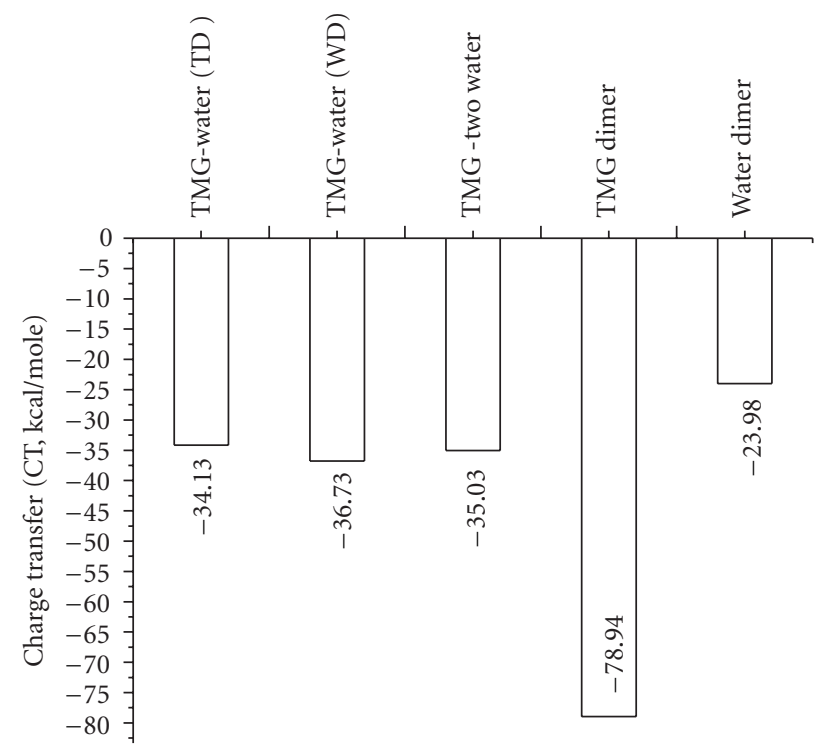

FIGURE 5: Bar chart of calculated charge transfer (CT, kcal/mol) by WB97XD/6-31++G(d,p) theory.

and intensity of hydrogen-bonded $\mathrm{O}-\mathrm{H}$ stretching for TMG dimer is higher than that of TMG $+\mathrm{n}$ water complex $(n=$ $1,2)$. It is also detected that the red shift and IR intensity of 


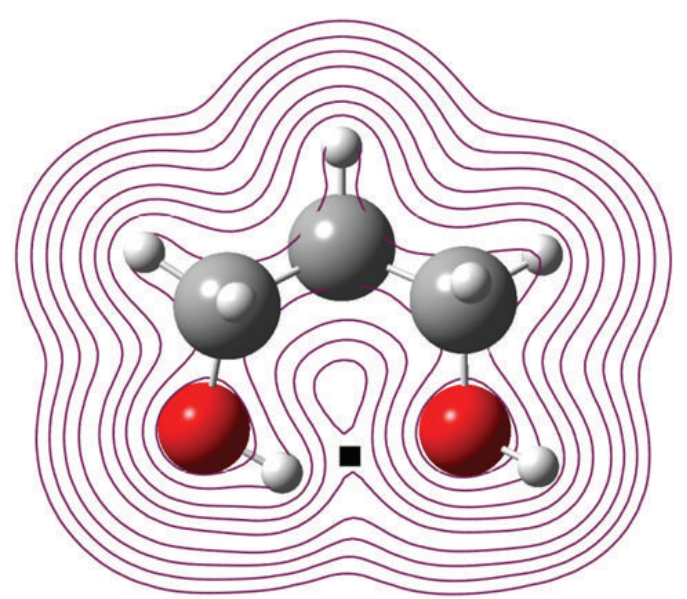

(a)

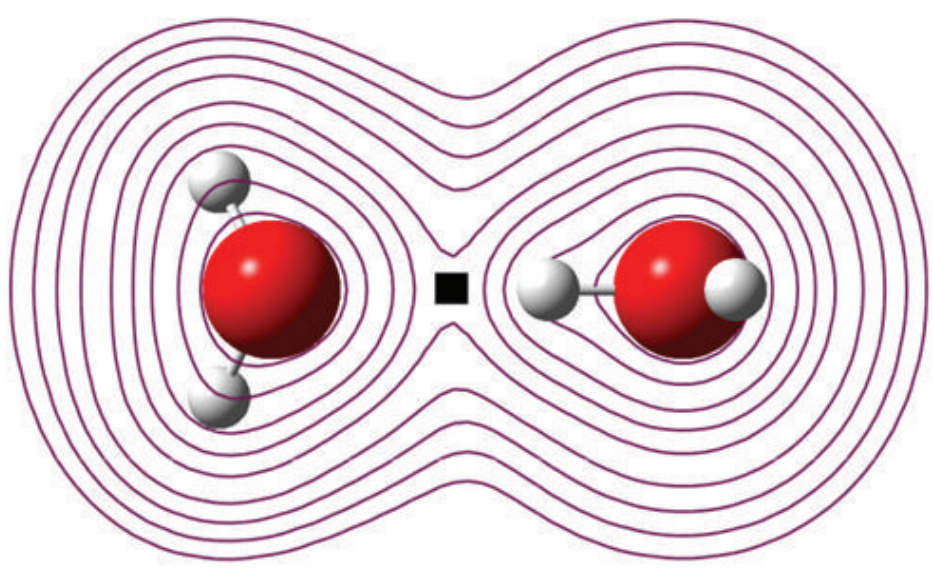

(b)

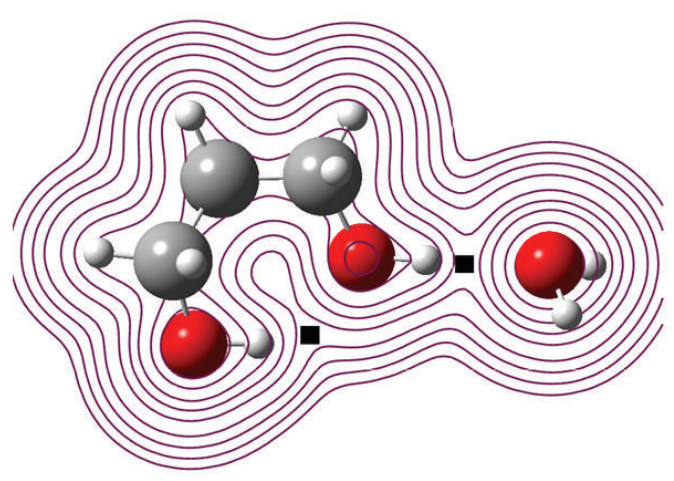

(c)

Figure 6: Contour map of the electron density for (a) single TMG molecule, (b) water dimer, (c) TMG +1 water complex (TD) by WB97XD/6-31++G(d,p) theory. Hydrogen bond critical points are indicated by filled square symbol, $\mathbf{\square}$ (colour legend: red = oxygen, black $=$ carbon and whitish grey $=$ hydrogen $)$.

TABle 5: Calculated total electron density $\left(\sum \rho\left(r_{c}\right),\left(e / a^{3}\right)\right)$, total Laplacian electron density $\left(\sum \nabla^{2} \rho\left(r_{c}\right),\left(e / a^{5}\right)\right)$ for TMG molecule, water dimer, and TMG + 1 water (TD) complex at hydrogen bond critical point (HBCP) using WB97XD/6-31++G(d,p).

\begin{tabular}{lcc}
\hline Systems & $\sum \rho\left(r_{c}\right)$ & $\sum \nabla^{2} \rho\left(r_{c}\right)$ \\
\hline Single TMG & 0.0220 & 0.0701 \\
Water dimer & 0.0228 & 0.0645 \\
TMG + 1 water complex (TD) & 0.0291 & 0.0771 \\
\hline
\end{tabular}

hydrogen-bonded O-H stretching of TMG molecule in TMG +1 water (TD) system are higher than that of $\mathrm{O}-\mathrm{H}$ stretching of water molecule in $\mathrm{TMG}+1$ water (WD) system. As higher values of red shift and intensity for hydrogen-bonded $\mathrm{O}-\mathrm{H}$ bond stretching indicate stronger hydrogen bond, intermolecular hydrogen bond in TMG +1 water (TD) system is stronger compared to the intermolecular hydrogen bond in TMG + 1 water (WD) system. Consequently, TMG has higher tendency to act as a proton donor to form hydrogen bond with water molecule.

\section{Conclusion}

A thorough analysis of hydrogen bond formation in trimethylene glycol (TMG) $+n$ water complex $(n=$ $1,2)$ has been performed based on calculated interaction energies, NBO, AIM, charge transfer, and red shift using HF, MP2, DFT, and DFT-D methods. TMG + 2 water complex, found to be most stable compared to TMG + 1 water complexes, TMG dimer, and water dimer as per calculated interaction energies. For TMG +1 water complex, stronger intermolecular hydrogen bond formed when TMG acts as a proton donor as per charge differences between respective hydrogen bond-forming atoms, $\mathrm{NBO}$ analysis, and red shifts of calculated vibrational spectra. The broadening as well as asymmetrical double minimum appearance in potential energy curve of hydrogen-bonded $\mathrm{O}-\mathrm{H}$ reveals that a moderately strong hydrogen bond $(\mathrm{O} 14 \cdots \mathrm{H} 13)$ is formed in TMG + 1 water complex (TD). Intermolecular hydrogen bond of TMG + 1 water complex (TD) has higher covalent character and accordingly, higher strength compared to that of TMG + 1 water complex (WD) as per HOMO-LUMO study. The hydrogen bond in TMG dimer 
TABLE 6: Calculated scaled vibrational frequency $\left(\mathrm{cm}^{-1}\right)$, red shift $\left(\mathrm{cm}^{-1}\right)$, IR intensity $\left(\mathrm{km}-\mathrm{mol}^{-1}\right)$ of O-H bond stretching for water molecule, and TMG molecule and TMG $+n$ water complex $(n=1,2)$ using WB97XD/6-31++G(d,p) along with some experimental vibrational frequency $\left(\mathrm{cm}^{-1}\right)$.

\begin{tabular}{|c|c|c|c|c|c|c|c|}
\hline \multirow{2}{*}{ System } & \multicolumn{4}{|c|}{$\mathrm{O}-\mathrm{H}$ bond stretching for water molecule } & \multicolumn{3}{|c|}{$\mathrm{O}-\mathrm{H}$ bond stretching for TMG molecule } \\
\hline & Scaled freq. & Red shift & IR intensity & Exp. vibrational frequency & Scaled freq. & Red shift & IR intensity \\
\hline Water molecule & 3802 & & 8.2 & $3756[9]$ & & & \\
\hline TMG molecule & & & & & 3757 & & 144.43 \\
\hline TMG dimer & & & & & 3519 & 238 & 585.61 \\
\hline TMG + 1 water complex (TD) & 3797 & 5 & 13.87 & & 3663 & 94 & 717.93 \\
\hline TMG + 1 water complex (WD) & 3736 & 66 & 95.97 & & 3754 & 3 & 80.39 \\
\hline TMG + 2 water complex & 3665 & 137 & 512.89 & & 3766 & - & 133.90 \\
\hline
\end{tabular}

is found to be stronger compared to other systems as per calculated charge transfer and red shift values. Very dilute TMG solution is recommended in order to break water cluster. This work illustrates electronic structure property correlation-based understandings of trimethylene glycol in aqueous solution and would help in designing inhibitors for water cluster/clathrate system like methane hydrate.

\section{Acknowledgments}

This work is financially supported by Ministry of Earth Science, Government of India (Project no. MoES/16/48/09RDEAS (MRDM5)). The authors also acknowledge Accelrys Inc. for providing free Discovery studio 3.1 visualization tool.

\section{References}

[1] P. Schuster and P. Wolschann, "Hydrogen bonding: from small clusters to biopolymers," Monatshefte fur Chemie, vol. 130, no. 8, pp. 947-960, 1999.

[2] G. A. Jeffrey, An Introduction to Hydrogen Bonding, Oxford University Press, New York, NY, USA, 1997.

[3] A. Demirbas, Methane Gas Hydrate, Springer, London, UK, 2010.

[4] T. S. Collett, "Energy resource potential of natural gas hydrates," AAPG Bulletin, vol. 86, no. 11, pp. 1971-1992, 2002.

[5] P. Englezos, "Clathrate hydrates," Industrial and Engineering Chemistry Research, vol. 32, no. 7, pp. 1251-1274, 1993.

[6] E. G. Hammerscht, "Formation of gas hydrates in natural gas transmission lines," Industrial \& Engineering Chemistry Research, vol. 26, no. 8, pp. 851-855, 1984.

[7] J. K. Fink, Petroleum Engineer's Guide to Oil Field Chemicals and Fluids, Elsevier, Oxford, UK, 2012.

[8] A. Wehner, R. Miller, G. Fenyvesi, J. W. DeSalvo, and M. Joerger, "Heat transfer compositions comprising renewable-based biodegradable 1, 3-propanediol," US patent 2007/0200088 A1, 2007.

[9] V. May and O. Kühn, Charge and Energy Transfer Dynamics in Molecular Systems, Wiley-VCH, Weinheim, Germany, 2005.

[10] S. J. Grabowski, T. L. Robinson, and J. Leszczynski, "Strong dihydrogen bonds-Ab initio and atoms in molecules study," Chemical Physics Letters, vol. 386, no. 1-3, pp. 44-48, 2004.

[11] S. Wojtulewski and S. J. Grabowski, "DFT and AIM studies on two-ring resonance assisted hydrogen bonds," Journal of Molecular Structure, vol. 621, no. 3, pp. 285-291, 2003.
[12] S. Pal and T. K. Kundu, "Dodecahedron methane hydrate cage structure-an Ab initio study," Journal of Petroleum Engineering and Technology, vol. 2, pp. 22-35, 2012.

[13] D. Peeters, "Hydrogen bonds in small water clusters: a theoretical point of view," Journal of Molecular Liquids, vol. 67, pp. 49-61, 1995.

[14] X. M. Zhou, Z. Y. Zhou, H. Fu, Y. Shi, and H. Zhang, "Density functional complete study of hydrogen bonding between the dichlorine monoxide and the hydroxyl radical $(\mathrm{Cl} 2 \mathrm{O} \cdot \mathrm{HO}), "$ Journal of Molecular Structure, vol. 714, no. 1, pp. 7-12, 2005.

[15] P. K. Sahu, A. Chaudhari, and S. L. Lee, "Theoretical investigation for the hydrogen bond interaction in THF-water complex," Chemical Physics Letters, vol. 386, no. 4-6, pp. 351355, 2004.

[16] P. K. Sahu and S. L. Lee, "Hydrogen-bond interaction in 1:1 complexes of tetrahydrofuran with water, hydrogen fluoride, and ammonia: a theoretical study," Journal of Chemical Physics, vol. 123, no. 4, Article ID 044308, 9 pages, 2005.

[17] A. Mandal, M. Prakash, R. M. Kumar, R. Parthasarathi, and V. Subramanian, "Ab Initio and DFT studies on methanol-water clusters," Journal of Physical Chemistry A, vol. 114, no. 6, pp. 2250-2258, 2010.

[18] J. E. Del Bene, "An ab initio study of the structures and enthalpies of the hydrogen-bonded complexes of the acids $\mathrm{H}_{2} \mathrm{O}, \mathrm{H}_{2} \mathrm{~S}, \mathrm{HCN}$, and $\mathrm{HCl}$ with the anions $\mathrm{OH}-, \mathrm{SH}-, \mathrm{CN}-$, and Cl-," Structural Chemistry, vol. 1, no. 1, pp. 19-27, 1990.

[19] I. Alkorta, F. Blanco, P. M. Deyà et al., "Cooperativity in multiple unusual weak bonds," Theoretical Chemistry Accounts, vol. 126, no. 1, pp. 1-14, 2010.

[20] I. Mata, E. Molins, I. Alkorta, and E. Espinosa, “Topological properties of the electrostatic potential in weak and moderate N. . H hydrogen bonds," Journal of Physical Chemistry A, vol. 111, no. 28, pp. 6425-6433, 2007.

[21] J. B. Levy, N. H. Martin, I. Hargittai, and M. Hargittai, "Intraand intermolecular hydrogen bonding in 2-phosphinylphenol: a quantum chemical study," Journal of Physical Chemistry A, vol. 102, no. 1, pp. 274-279, 1998.

[22] O. V. Shishkin, I. S. Konovalova, L. Gorb, and J. Leszczynski, "Novel type of mixed O-H $\cdots$ N/O-H $\cdots \pi$ hydrogen bonds: monohydrate of pyridine," Structural Chemistry, vol. 20, no. 1, pp. 37-41, 2009.

[23] V. Horváth, A. Kovács, and I. Hargittai, "Structural aspects of donor-acceptor interactions," Journal of Physical Chemistry A, vol. 107, no. 8, pp. 1197-1202, 2003.

[24] C. C. J. Roothaan, "New developments in molecular orbital theory," Reviews of Modern Physics, vol. 23, no. 2, pp. 69-89, 1951. 
[25] M. Head-Gordon, J. A. Pople, and M. J. Frisch, "MP2 energy evaluation by direct methods," Chemical Physics Letters, vol. 153, no. 6, pp. 503-506, 1988.

[26] P. Hohenberg and W. Kohn, "Inhomogeneous electron gas," Physical Review, vol. 136, no. 3, pp. B864-B871, 1964.

[27] W. Kohn and L. J. Sham, "Self-consistent equations including exchange and correlation effects," Physical Review, vol. 140, no. 4, pp. A1133-A1138, 1965.

[28] S. Grimme, "Accurate description of van der Waals complexes by density functional theory including empirical corrections," Journal of Computational Chemistry, vol. 25, no. 12, pp. 1463 1473,2004

[29] A. D. Becke, "Density-functional exchange-energy approximation with correct asymptotic behavior," Physical Review A, vol. 38, no. 6, pp. 3098-3100, 1988.

[30] C. Lee, W. Yang, and R. G. Parr, "Development of the ColleSalvetti correlation-energy formula into a functional of the electron density," Physical Review B, vol. 37, no. 2, pp. 785789, 1988.

[31] J. D. Chai and M. Head-Gordon, "Long-range corrected hybrid density functionals with damped atom-atom dispersion corrections," Physical Chemistry Chemical Physics, vol. 10, no. 44, pp. 6615-6620, 2008.

[32] Y. Zhao and D. G. Truhlar, "The M06 suite of density functionals for main group thermochemistry, thermochemical kinetics, noncovalent interactions, excited states, and transition elements: two new functionals and systematic testing of four M06-class functionals and 12 other functionals," Theoretical Chemistry Accounts, vol. 120, no. 1-3, pp. 215-241, 2008.

[33] P. C. Hariharan and J. A. Pople, "The influence of polarization functions on molecular orbital hydrogenation energies," Theoretica Chimica Acta, vol. 28, no. 3, pp. 213-222, 1973.

[34] J. Chandrasekhar, J. G. Andrade, and P. Von Ragué Schleyer, "Efficient and accurate calculation of anion proton affinities," Journal of the American Chemical Society, vol. 103, no. 18, pp. 5609-5612, 1981.

[35] M. S. Gordon and J. H. Jensen, "Understanding the hydrogen bond using quantum chemistry," Accounts of Chemical Research, vol. 29, no. 11, pp. 536-543, 1996.

[36] S. F. Boys and F. Bernardi, "The calculation of small molecular interactions by the differences of separate total energies. Some procedures with reduced errors," Molecular Physics, vol. 19, no. 4, pp. 553-566, 1970.

[37] F. Weinhold and C. R. Landis, "Natural bond orbitals and extensions of localized bonding concepts," Chemistry Education Research and Practice, vol. 2, pp. 91-104, 2001.

[38] E. D. Gledening, A. E. Reed, J. A. Carpenter, and F. Weinhold, NBO. version 3.1.

[39] A. E. Reed, L. A. Curtiss, and F. Weinhold, "Intermolecular interactions from a natural bond orbital, donor-acceptor viewpoint," Chemical Reviews, vol. 88, no. 6, pp. 899-926, 1988.

[40] A. Y. Li, "Chemical origin of blue- and red shifted hydrogen bonds: intra-molecular hyper-conjugation and its coupling with intermolecular hyper-conjugation," Journal of Chemical Physics, vol. 126, pp. 154102-154111, 2007.

[41] R. F. W. Bader, "Atoms in molecules," Accounts of Chemical Research, vol. 18, pp. 9-15, 1985.

[42] M. J. Frisch, G. W. Trucks, H. B. Schlegel et al., "Gaussian 09, Revision (B.01),” Gaussian Inc., Wallingford CT, 2010.

[43] I. M. Alecu, J. Zheng, Y. Zhao, and D. G. Truhlar, "Computational thermochemistry: scale factor databases and scale factors for vibrational frequencies obtained from electronic model chemistries," Journal of Chemical Theory and Computation, vol. 6, no. 9, pp. 2872-2887, 2010.

[44] B. Civalleri, C. M. Zicovich-Wilson, L. Valenzano, and P. Ugliengo, "B3LYP augmented with an empirical dispersion term (B3LYP-D*) as applied to molecular crystals," CrystEngComm, vol. 10, no. 4, pp. 405-410, 2008.

[45] A. E. Lutskii and N. I. Gorokhova, "Intramolecular hydrogen bonds and molecular dipole moments," Theoretical and Experimental Chemistry, vol. 4, no. 6, pp. 532-534, 1971.

[46] H. Umeyama and K. Morokuma, "Origin of alkyl substituent effect in the proton affinity of amines, alcohols, and ethers," Journal of the American Chemical Society, vol. 98, no. 15, pp. 4400-4404, 1976.

[47] H. Umeyama and K. Morokuma, "The origin of hydrogen bonding. An energy decomposition study," Journal of the American Chemical Society, vol. 99, no. 5, pp. 1316-1332, 1977.

[48] A. Van der Vaart and K. M. Merz Jr., "Charge transfer in small hydrogen bonded clusters," Journal of Chemical Physics, vol. 116, no. 17, pp. 7380-7388, 2002.

[49] S. J. Grabowski, Hydrogen Bonding-New Insights, Springer, Dordrecht, The Netherlands, 2006. 


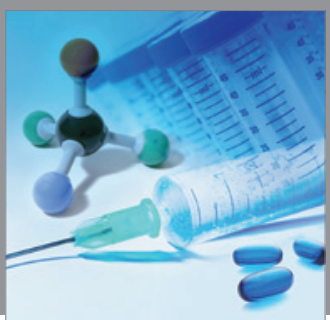

International Journal of

Medicinal Chemistry

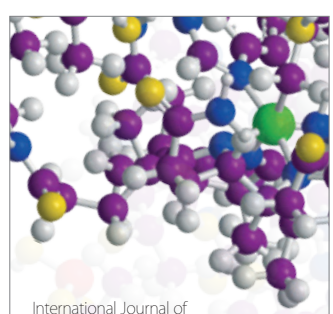

Carbohydrate Chemistry

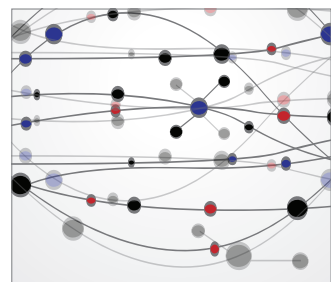

The Scientific World Journal
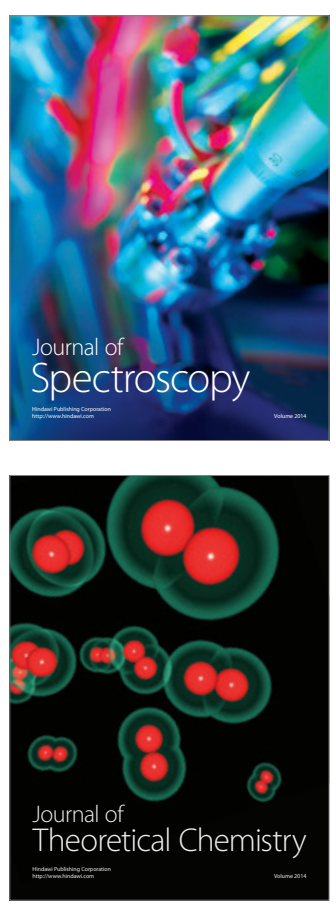
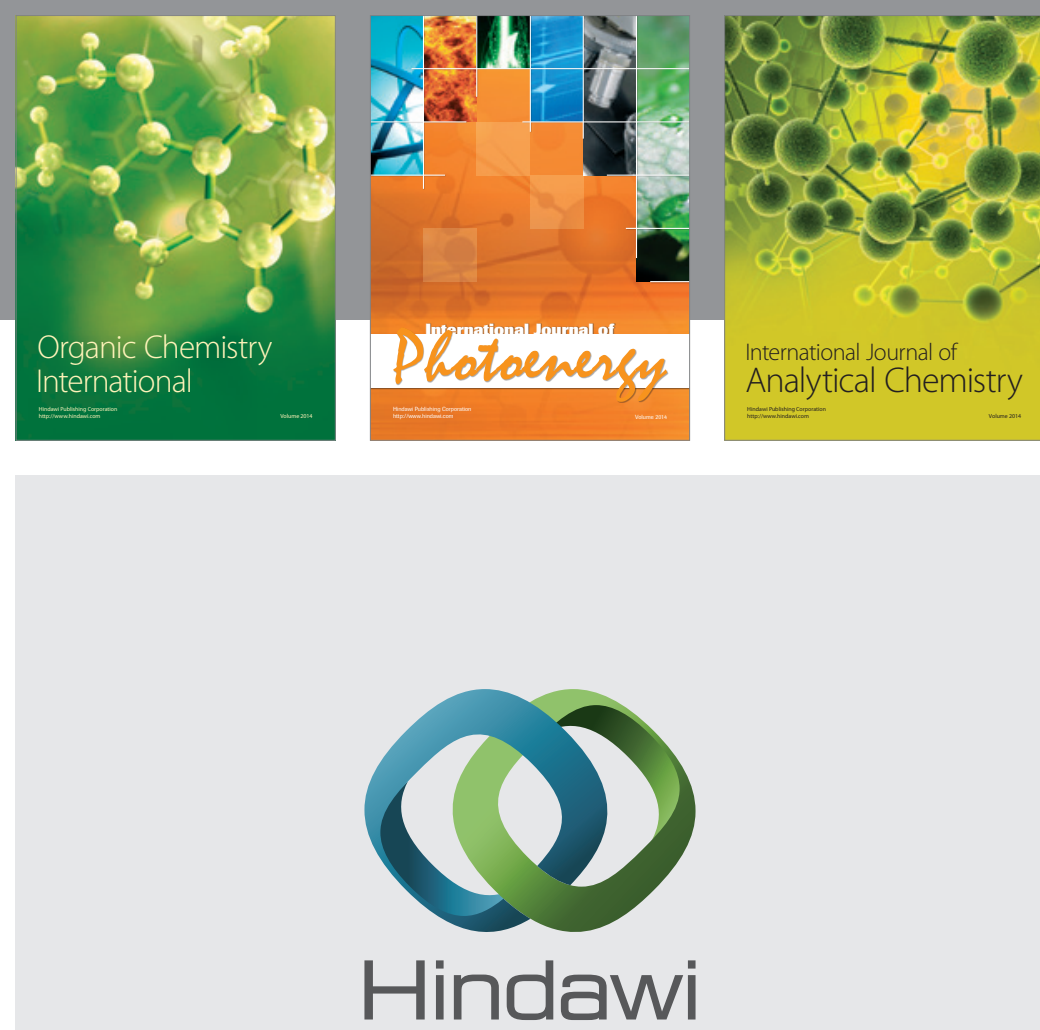

Submit your manuscripts at

http://www.hindawi.com
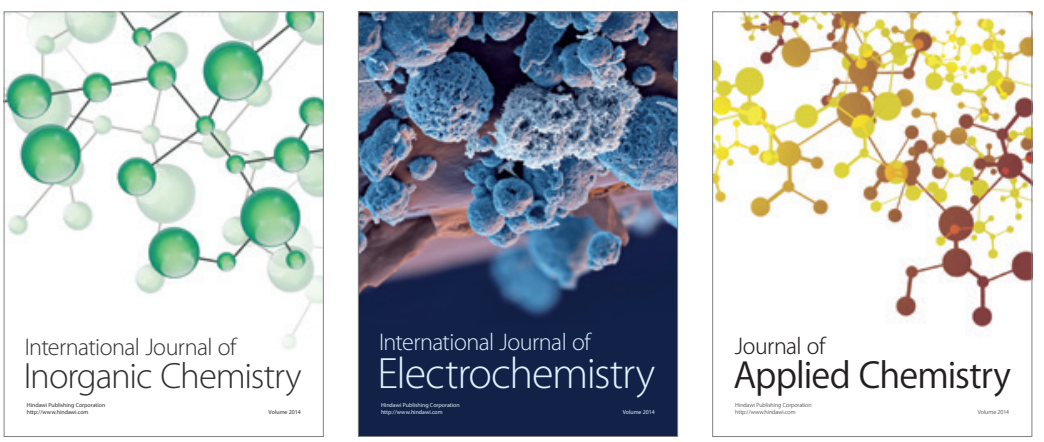

Journal of

Applied Chemistry
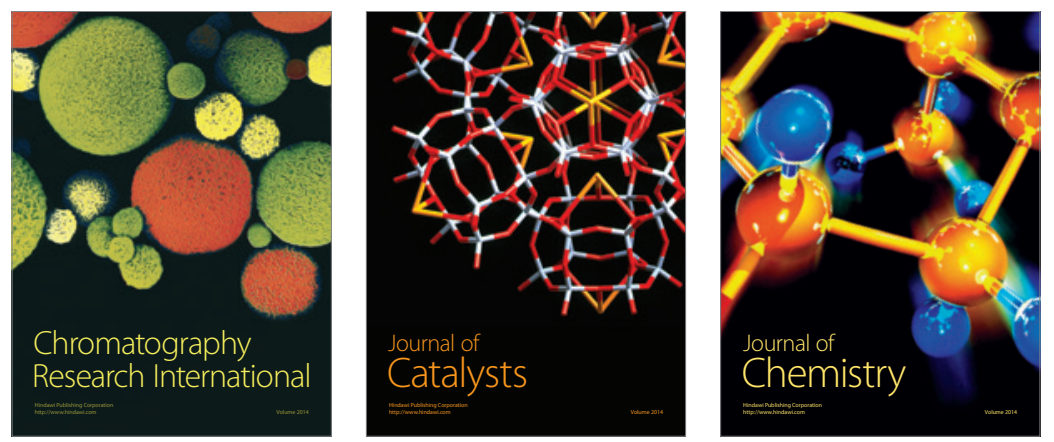
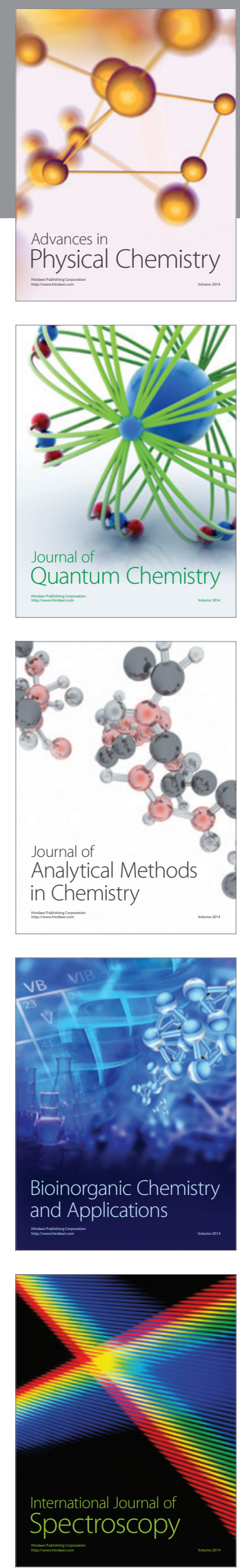